(2) Open Access Full Text Article

\title{
Impact of Dry Eye Disease on Work Productivity Among Saudi Workers in Saudi Arabia
}

\author{
Faris H Binyousef $\left(\mathbb{D}^{\prime}\right.$ \\ Shahad A Alruwaili (D)' \\ Abdulaziz F Altammami $\mathbb{D}^{\prime}$ \\ Ahmed A Alharbi (D) \\ Feras A Alrakaf (D) \\ Abdulrhman A Almazrou $\mathbb{D}^{2}$ \\ 'College of Medicine, Imam Mohammad \\ Ibn Saud Islamic University, Riyadh, Saudi \\ Arabia; ${ }^{2}$ Ophthalmology Department, \\ College of Medicine, Imam Mohammad \\ Ibn Saud Islamic University, Riyadh, Saudi \\ Arabia
}

Correspondence: Shahad A Alruwaili College of Medicine, Imam Mohammad Ibn Saud Islamic University, Riyadh, Saudi Arabia

Tel/Fax +966534479993

Email shahadabdullahalr@gmail.com
Purpose: To assess the impact of dry eye disease (DED) on work productivity in Saudi Arabia and investigate its effect on daily activities.

Patients and Methods: We conducted a cross-sectional study on male and female Saudi workers age 20 years or older. The data were collected via self-administered questionnaires distributed electronically through social media. We used the Ocular Surface Disease Index questionnaire to diagnose DED patients and assess their DED severity as mild, moderate, and severe.

Results: A total of 463 respondents qualified for the study. All patients in the DED groups reported a loss of work productivity. Most patients in the severe DED group (59\%) reported difficulty focusing on work due to DED, whereas $17.1 \%$ of patients with mild DED and $22.7 \%$ with moderate DED reported the same. These findings indicate significantly worsening productivity as DED progresses in severity $(\mathrm{p}<0.05)$. Participants with severe DED reported significantly more affected work hours weekly $(35.8 \%)$ than participants with moderate $(6.1 \%)$ and mild DED (7.1\%).

Conclusion: DED has a significant impact on work productivity, with the most pronounced effect among office workers. It is essential to screen office workers for DED and enhance the awareness of its effect on work productivity among the workforce and healthcare providers.

Keywords: dry eye syndrome, work performance, office worker, presenteeism, occupation

\section{Introduction}

Dry eye disease (DED), or keratoconjunctivitis sicca, is a multifactorial disease that is considered a growing public health concern characterized by inflammation of the ocular surface with a high osmolarity of the tear film. ${ }^{1,2}$ DED affects the ocular surface, meibomian glands, the main lacrimal gland, and the innervation between them. ${ }^{3}$ In the past, DED was considered a condition of decreased tear volume, but it is now understood as an abnormality in the tear composition, where the tear has lost the ability to support the ocular surface. DED can be classified as episodic or chronic. Episodic DED arises from many factors, such as prolonged visual tasks with reduced blinking. Chronic DED is exacerbated by the same factors as episodic, but symptoms continuously persist.

DED symptoms are often increased by prolonged visual effort or exposure to any triggering factor. ${ }^{4}$ Symptoms can include burning, itching, photophobia, redness, foreign body sensation, pruritus, and blurred vision. In the late stages of the condition, corneal complications can occur. The effects on visual performance may significantly contribute to decreased quality of life in DED patients and reduced performance in many daily activities like driving, watching television (TV), using 
a computer, cooking, and reading. ${ }^{5,6} \mathrm{DED}$ is one of the most prevalent ocular diseases worldwide, ${ }^{7}$ occurring in $4.4 \%$ to $50 \%$ of the world's population. ${ }^{8,9}$ The broad range in incidence is due to variations in the population investigated, geographical differences, and the differences in the methods and definitions used. According to a recent study, the prevalence of DED in Saudi Arabia is $32.1 \%{ }^{10}$ Generally, DED is one of the leading reasons patients seek care from ophthalmologists and optometrists. ${ }^{5}$

Many factors are positively associated with DED, including older age, female, air pollution, low humidity, contact lens use, smoking, and extended digital device screen exposure. ${ }^{11,12}$ Many medical conditions are significant risk factors for DED, like depression, history of ocular surgery, cancer treatment, antidepressant, and antiallergy medications. ${ }^{12,13}$ Patient education is an essential factor in managing DED, and the avoidance of exacerbating factors is an integral part of the treatment plan. In general, artificial tears are the mainstay of therapy for all severity levels of DED. ${ }^{3}$

Given the high prevalence of DED among the workingage population, with an increased risk, particularly in workers with more visual display terminals usage, it is important to address the impact of DED, as it might have considerable effects on work productivity. ${ }^{14,15}$ The socioeconomic burden of DED on the patients can have direct costs (eg, treatment fees) and indirect costs (eg, absence from work and impaired work performance). ${ }^{16}$ DED may affect working productivity in two different ways, either by presenteeism, which is the loss of work productivity in the attending workers, or absenteeism, which is the patient's absence from work. ${ }^{17}$ With this in mind, we conducted the present study to assess the impact of DED on work productivity among a Saudi Arabian population.

\section{Patients and Methods}

This cross-sectional study was conducted from August 2020 to March 2021. Four hundred sixty-three Saudi workers were enrolled in the study. Prior to data collection, institutional review board approval was obtained from Imam Muhammad bin Saud Research Ethics Committee in Riyadh City. We explained the study objectives to the participants and obtained their voluntary consent before enrolling them in the study. The data were collected via an online questionnaire, that has been disrupted randomly through online platforms. Participants younger than age 20 years and those who did not provide informed consent were excluded.
Participants were asked to complete a self-reported questionnaire that included demographic variables (eg, age, sex, marital status, education, and job). The participants also answered questions about their physical health, comorbidities, and pharmacotherapy.

The diagnosis and severity assessment of DED was based on the Ocular Surface Disease Index (OSDI) questionnaire, a well-developed validated tool to assess DED. ${ }^{18}$ The Arabic version of the questionnaire was used after it was developed and pretested by a pilot study. The OSDI is a 12-item questionnaire that assesses patients on a scale of 0 to 100 , with higher scores representing greater disability. OSDI scores of 13 to 22 indicate mild DED, scores of 23 to 32 indicate moderate DED, and scores of 33 or greater indicate severe DED. Participants with an OSDI score below 13 were excluded from the study for not meeting the minimum score to be classified as mild DED. Statistical analysis was done using IBM SPSS Statistics for Windows, Version 22.0 (Armonk, NY: IBM Corp.). We used the chi-square test to attain a p-value between categorical dependent and independent data to estimate the association where $\mathrm{p} \leq 0.05$ is considered significant.

\section{Patient and Public Involvement}

Participants from the public were enrolled in the study only to participate in completing a self-administered survey after providing informed consent. No further public contribution was involved in the study.

\section{Results}

Patient Demographics: A total of 463 participants with concerns about DED completed the survey. The study sample covered several age groups, including 150 respondents $(32.4 \%)$ aged 21 to 30 years, 124 respondents (26.8\%) aged 31 to 40 years, 146 respondents $(31.5 \%)$ aged 41 to 50 years, and 43 respondents (9.3\%) older than age 50 years. Most survey respondents were women $(\mathrm{n}=316,68.3 \% ; 147$ men, 31.7\%), and most respondents were nonsmokers $(n=377,81.4 \%$; 86 smokers, $18.6 \%)$.

DED Severity: Nearly half of all respondents (49.5\%) indicated a prior diagnosis of DED, while the remainder $(51 \%)$ reported they had not been diagnosed with DED. Most respondents with DED had severe DED (70.6\%), $14.3 \%$ reported moderate $\mathrm{DED}$, and $15.1 \%$ reported mild DED.

DED Factors: Table 1 presents demographic factors and their association with DED severity. Neither age nor smoking status significantly affected DED severity 
Table I The Demographic Factors and Dry Eye Disease Severity

\begin{tabular}{|c|c|c|c|c|c|c|c|c|}
\hline & & \multicolumn{6}{|c|}{ Severity of Dry Eye } & \multirow{3}{*}{ P-value } \\
\hline & & \multicolumn{2}{|c|}{ Mild } & \multicolumn{2}{|c|}{ Moderate } & \multicolumn{2}{|c|}{ Severe } & \\
\hline & & Count & Percent & Count & Percent & Count & Percent & \\
\hline \multirow[t]{4}{*}{ Age (years) } & $20-30$ & 31 & $44.3 \%$ & 24 & $36.4 \%$ & 95 & $29.1 \%$ & 0.070 \\
\hline & $31-40$ & 21 & $30.0 \%$ & 18 & $27.3 \%$ & 85 & $26.0 \%$ & \\
\hline & $4 I-50$ & 12 & $17.1 \%$ & 20 & $30.3 \%$ & 114 & $34.9 \%$ & \\
\hline & $>50$ & 6 & $8.6 \%$ & 4 & $6.1 \%$ & 33 & $10.1 \%$ & \\
\hline \multirow[t]{2}{*}{ Sex } & Male & 26 & $37.1 \%$ & 33 & $50.0 \%$ & 88 & $26.9 \%$ & $0.001 *$ \\
\hline & Female & 44 & $62.9 \%$ & 33 & $50.0 \%$ & 239 & $73.1 \%$ & \\
\hline \multirow[t]{2}{*}{ Smoking } & Yes & 19 & $27.1 \%$ & 14 & $21.2 \%$ & 53 & $16.2 \%$ & 0.086 \\
\hline & No & 51 & $72.9 \%$ & 52 & $78.8 \%$ & 274 & $83.8 \%$ & \\
\hline
\end{tabular}

Note: ${ }^{*}<0.05$.

( $\mathrm{p}=0.070$ and $\mathrm{p}=0.086$, respectively). However, sex had a significant effect on DED severity as $73.1 \%$ of those with severe DED were women compared with only $26.9 \%$ of severe DED reported in men $(\mathrm{p}=0.001)$.
Table 2 presents employment factors and DED severity. Employment status had no significant effect on the severity of DED ( $p=0.721)$. However, office workers had a higher incidence of severe DED than field workers

Table 2 Employment Factors and Dry Eye Disease Severity

\begin{tabular}{|c|c|c|c|c|c|c|c|c|c|}
\hline & & \multirow{3}{*}{$\begin{array}{l}\text { Incidence } \\
(\%)\end{array}$} & \multicolumn{6}{|c|}{ Severity of Dry Eye } & \multirow[t]{3}{*}{ P-value } \\
\hline & & & \multicolumn{2}{|c|}{ Mild } & \multicolumn{2}{|c|}{ Moderate } & \multicolumn{2}{|c|}{ Severe } & \\
\hline & & & Count & Percent & Count & Percent & Count & Percent & \\
\hline \multirow[t]{2}{*}{ Employment status } & University student & $90(19.4 \%)$ & 16 & $17.8 \%$ & 13 & $14.4 \%$ & 61 & $67.8 \%$ & 0.721 \\
\hline & Employee & $373(80.6 \%)$ & 54 & $14.5 \%$ & 53 & $14.2 \%$ & 266 & $71.3 \%$ & \\
\hline \multirow{2}{*}{$\begin{array}{l}\text { Employment type (students } \\
\text { excluded) }\end{array}$} & Office worker & $307(82.3 \%)$ & 42 & $13.7 \%$ & 34 & $11.1 \%$ & 231 & $75.2 \%$ & $0.000 *$ \\
\hline & Field worker & $66(17.7 \%)$ & 12 & $18.2 \%$ & 19 & $28.8 \%$ & 35 & $53.0 \%$ & \\
\hline \multirow[t]{5}{*}{ Work experience (years) } & $1-5$ & $83(17.9 \%)$ & 18 & $21.7 \%$ & 13 & $15.7 \%$ & 52 & $62.7 \%$ & 0.347 \\
\hline & $6-10$ & $97(21.0 \%)$ & 14 & $14.4 \%$ & 9 & $9.3 \%$ & 74 & $76.3 \%$ & \\
\hline & $11-15$ & $55(11.9 \%)$ & 7 & $12.7 \%$ & 10 & $18.2 \%$ & 38 & $69.1 \%$ & \\
\hline & $>15$ & $153(33.0 \%)$ & 17 & $11.1 \%$ & 24 & $15.7 \%$ & 112 & $73.2 \%$ & \\
\hline & Not employed & $75(16.2 \%)$ & 14 & $18.7 \%$ & 10 & $13.3 \%$ & 51 & $68.0 \%$ & \\
\hline \multirow[t]{4}{*}{ Time spent at work daily } & $<4$ hours & 17 (3.7\%) & 6 & $35.3 \%$ & 0 & $0.0 \%$ & 11 & $64.7 \%$ & $0.014 *$ \\
\hline & $4-6$ hours & 146 (31.5\%) & 23 & $15.8 \%$ & 17 & $11.6 \%$ & 106 & $72.6 \%$ & \\
\hline & $7-8$ hours & $232(50.1 \%)$ & 27 & $11.6 \%$ & 34 & $14.7 \%$ & $17 \mid$ & $73.7 \%$ & \\
\hline & $>8$ hours & $68(14.7 \%)$ & 6 & $35.3 \%$ & 0 & $0.0 \%$ & 11 & $64.7 \%$ & \\
\hline \multirow{5}{*}{$\begin{array}{l}\text { Time spent on electronic } \\
\text { devices at work daily }\end{array}$} & $<2$ hours & $59(12.7 \%)$ & 12 & $20.3 \%$ & 8 & $13.6 \%$ & 39 & $66.1 \%$ & 0.103 \\
\hline & $2-4$ hours & $122(26.3 \%)$ & 22 & $18.0 \%$ & 22 & $18.0 \%$ & 78 & $63.9 \%$ & \\
\hline & $4-6$ hours & 127 (27.4\%) & 17 & $13.4 \%$ & 21 & $16.5 \%$ & 89 & $70.1 \%$ & \\
\hline & $7-8$ hours & $96(20.7 \%)$ & 16 & $16.7 \%$ & 10 & $10.4 \%$ & 70 & $72.9 \%$ & \\
\hline & $>8$ hours & $59(12.7 \%)$ & 3 & $5.1 \%$ & 5 & $8.5 \%$ & 51 & $86.4 \%$ & \\
\hline \multirow{4}{*}{$\begin{array}{l}\text { The electronic device used } \\
\text { the most in during the day }\end{array}$} & Desktop Computer & $137(29.6 \%)$ & 21 & $15.3 \%$ & 18 & $13.1 \%$ & 98 & $71.5 \%$ & 0.559 \\
\hline & Laptops & $68(14.7 \%)$ & 9 & $13.2 \%$ & 10 & $14.7 \%$ & 49 & $72.1 \%$ & \\
\hline & Tablets & II (2.4\%) & 1 & $9.1 \%$ & 4 & $36.4 \%$ & 6 & $54.5 \%$ & \\
\hline & Smartphone & 247 (53.3\%) & 39 & $15.8 \%$ & 34 & $13.8 \%$ & 174 & $70.4 \%$ & \\
\hline
\end{tabular}

Note: ${ }^{*}<0.05$ 
(nonoffice worker) (75.2\% vs 53.0\%). Higher incidences of severe DED correlated to longer durations of work in an office ( $\mathrm{p}=0.014)$.

In Table 3, the comorbidities of respondents are correlated to DED incidence and severity. Patients with comorbid conditions are significantly more likely to have severe DED. Diabetes was the most common comorbidity (95.2\%) among respondents with severe DED. High cholesterol and thyroid disorders were also major comorbidities among respondents with severe DED. Undergoing a vision correction operation or wearing contact lenses did not affect DED severity $(\mathrm{p}=0$. 241 and $\mathrm{p}=0.722$, respectively). The use of lubricant eye drops was more prevalent in respondents with severe DED than mild or moderate DED.

Association of DED With Work Productivity and Daily Activities: As noted in Table 4, the severity of DED had no significant effect on missing a working day, and a DED did not force most of the participants to miss a day of work (92.4\%). Among respondents, 72.8\% reported that DED did not affect their functional performance, while $17.5 \%$ reported that DED affected performance 1 to 2 hours daily. Nearly half (47.5\%) of participants reported that they faced difficulty focusing due to DED, and DED severity affected the level of difficulty in focusing. Moreover, $67.2 \%$ of respondents indicated they had to take a break during work because of DED, and those with severe DED were significantly more in need of a break (78.6\%) than the mild DED group $(38.6 \% ; \mathrm{p}=0.00)$. Additionally, it seems that DED caused many patients $(62.4 \%)$ to stay away from air-conditioning or make other changes in the work environment to reduce DED symptoms. Severe DED patients who reported that they have to make changes in the work environment represent $76.1 \%$ of this population compared to $32.9 \%$ of those with mild DED ( $p=0.00)$. Finally, when the respondents were asked to self-grade the impact of DED on work performance during the past week on a scale of 1 to 10 , with 10 being the worst, DED severity had a significant effect on work performance - the more severe the DED, the higher the negative impact on performance.

Moreover, DED limited the performance of some daily habits, as $9.6 \%$ of respondents indicated that DED limited reading at all times, $11.3 \%$ reported DED limited reading most of the time, and $34.7 \%$ felt that DED limited their reading approximately half of the time $(p=0.00)$. Driving at night has also been impaired by DED, where $5.8 \%$ of the sample had this problem always, $8 \%$ had it most of the time, and $23.4 \%$ had it half of the time. Watching TV or working on a computer are other daily habits that have been affected by DED, where only $14.4 \%$ and $17.5 \%$, respectively, of

Table 3 Participant Health and Dry Eye Severity

\begin{tabular}{|c|c|c|c|c|c|c|c|c|c|}
\hline & & \multirow[t]{3}{*}{ Incidence (\%) } & \multicolumn{6}{|c|}{ Severity of Dry Eye } & \multirow[t]{3}{*}{ P-value } \\
\hline & & & \multicolumn{2}{|c|}{ Mild } & \multicolumn{2}{|c|}{ Moderate } & \multicolumn{2}{|c|}{ Severe } & \\
\hline & & & Count & Percent & Count & Percent & Count & Percent & \\
\hline \multirow{7}{*}{$\begin{array}{l}\text { Comorbid } \\
\text { condition }\end{array}$} & Hypo/hyperthyroidism & 39 (8.4\%) & 3 & $7.7 \%$ & 4 & $10.3 \%$ & 32 & $82.1 \%$ & $0.004 *$ \\
\hline & Rheumatoid arthritis & $16(3.5 \%)$ & 3 & $18.8 \%$ & 3 & $17.8 \%$ & 10 & $62.5 \%$ & \\
\hline & Diabetes mellitus & 21 (4.5\%) & 1 & $4.7 \%$ & 0 & $0.0 \%$ & 20 & $95.2 \%$ & \\
\hline & High cholesterol & $57(12.3 \%)$ & 6 & $10.5 \%$ & 3 & $5.3 \%$ & 48 & $84.2 \%$ & \\
\hline & Myopia/hyperopia & $160(34.6 \%)$ & 22 & $13.8 \%$ & 24 & $15 \%$ & 114 & $71.3 \%$ & \\
\hline & Astigmatism & 42 (9.1\%) & 4 & $9.5 \%$ & 10 & $23.8 \%$ & 28 & $66.7 \%$ & \\
\hline & No comorbid conditions & $128(27.6 \%)$ & 31 & $24.2 \%$ & 22 & $17.2 \%$ & 75 & $58.7 \%$ & \\
\hline \multirow{2}{*}{$\begin{array}{l}\text { Undergone vision } \\
\text { correction } \\
\text { operations }\end{array}$} & Yes & $108(23.3 \%)$ & 14 & $13.0 \%$ & II & $10.2 \%$ & 83 & $76.9 \%$ & $0.24 I$ \\
\hline & No & 355 (76.7\%) & 56 & $15.8 \%$ & 55 & $15.5 \%$ & 244 & $68.7 \%$ & \\
\hline \multirow[t]{2}{*}{ Contact lens use } & Yes & 99 (2I.4\%) & 13 & $13.1 \%$ & 16 & $16.2 \%$ & 70 & $70.7 \%$ & 0.722 \\
\hline & No & 364 (78.6\%) & 57 & $15.7 \%$ & 50 & $13.7 \%$ & 257 & $70.6 \%$ & \\
\hline \multirow{2}{*}{$\begin{array}{l}\text { Lubricant eye drops } \\
\text { use }\end{array}$} & Yes & 279 (60.3\%) & 30 & $10.8 \%$ & 33 & $11.8 \%$ & 216 & $77.4 \%$ & $0.00 *$ \\
\hline & No & 184 (39.7\%) & 40 & $21.8 \%$ & 33 & $17.9 \%$ & 111 & $60.3 \%$ & \\
\hline
\end{tabular}

Note: ${ }^{*} p<0.05$ 
Table 4 The Impact of Dry Eye Disease on Work Productivity

\begin{tabular}{|c|c|c|c|c|c|c|c|c|c|}
\hline & & \multirow{3}{*}{$\begin{array}{l}\text { Incidence } \\
(\%)\end{array}$} & \multicolumn{6}{|c|}{ Severity of Dry Eye } & \multirow[t]{3}{*}{ P-value } \\
\hline & & & \multicolumn{2}{|c|}{ Mild } & \multicolumn{2}{|c|}{ Moderate } & \multicolumn{2}{|c|}{ Severe } & \\
\hline & & & Count & Percent & Count & Percent & Count & Percent & \\
\hline \multirow{5}{*}{$\begin{array}{l}\text { Work hours missed due to dry eye } \\
\text { weekly }\end{array}$} & $1-2$ & $23(5.0 \%)$ & 3 & $4.3 \%$ & 0 & $0.0 \%$ & 20 & $6.1 \%$ & \multirow[t]{5}{*}{0.094} \\
\hline & $3-5$ & $2(0.4 \%)$ & 0 & $0.0 \%$ & 0 & $0.0 \%$ & 2 & $0.6 \%$ & \\
\hline & $6-8$ & $8(1.8 \%)$ & 0 & $0.0 \%$ & 0 & $0.0 \%$ & 8 & $2.5 \%$ & \\
\hline & $>8$ & $2(0.4 \%)$ & 1 & $1.4 \%$ & I & $1.5 \%$ & 0 & $0.0 \%$ & \\
\hline & $\begin{array}{l}\text { I do not miss work } \\
\text { because of dry eyes }\end{array}$ & $428(92.4 \%)$ & 66 & $94.3 \%$ & 65 & $98.5 \%$ & 297 & $90.8 \%$ & \\
\hline \multirow{5}{*}{$\begin{array}{l}\text { Work hours affected due to dry eye } \\
\text { weekly }\end{array}$} & $1-2$ & 81 (17.5\%) & 2 & $2.9 \%$ & 3 & $4.5 \%$ & 76 & $23.2 \%$ & \multirow[t]{5}{*}{$0.00^{*}$} \\
\hline & $3-5$ & $23(5.0 \%)$ & 3 & $4.3 \%$ & 1 & $1.5 \%$ & 19 & $5.8 \%$ & \\
\hline & $6-8$ & $13(2.8 \%)$ & 0 & $0.0 \%$ & 0 & $0.0 \%$ & 13 & $4.0 \%$ & \\
\hline & $>8$ & $9(1.9 \%)$ & 0 & $0.0 \%$ & 0 & $0.0 \%$ & 9 & $2.8 \%$ & \\
\hline & $\begin{array}{l}\text { My functional } \\
\text { performance is not } \\
\text { affected by dry eyes }\end{array}$ & 337 (72.8\%) & 65 & $92.9 \%$ & 62 & $93.9 \%$ & 210 & $64.2 \%$ & \\
\hline \multirow{2}{*}{$\begin{array}{l}\text { Face difficulty in focusing due to dry } \\
\text { eye }\end{array}$} & Yes & $220(47.5 \%)$ & 12 & $17.1 \%$ & 15 & $22.7 \%$ & 193 & $59.0 \%$ & \multirow[t]{2}{*}{$0.00 *$} \\
\hline & No & 243 (52.5\%) & 58 & $82.9 \%$ & 51 & $77.3 \%$ & 134 & $41.0 \%$ & \\
\hline \multirow{2}{*}{$\begin{array}{l}\text { Take a break from work due to dry } \\
\text { eye }\end{array}$} & Yes & $311(67.2 \%)$ & 27 & $38.6 \%$ & 27 & $40.9 \%$ & 257 & $78.6 \%$ & \multirow[t]{2}{*}{$0.00 *$} \\
\hline & No & 152 (32.8\%) & 43 & $61.4 \%$ & 39 & $59.1 \%$ & 70 & $21.4 \%$ & \\
\hline \multirow{2}{*}{$\begin{array}{l}\text { Need to stay away from air- } \\
\text { conditioning, office equipment, or } \\
\text { make any other changes in the work } \\
\text { environment to improve dry eye }\end{array}$} & Yes & 289 (62.4\%) & 23 & $32.9 \%$ & 17 & $25.8 \%$ & 249 & $76.1 \%$ & \multirow[t]{2}{*}{$0.00^{*}$} \\
\hline & No & 174 (37.6\%) & 47 & $67.1 \%$ & 49 & $74.2 \%$ & 78 & $23.9 \%$ & \\
\hline $\begin{array}{l}\text { Impact of dry eye on work } \\
\text { performance during past week }(0-10)\end{array}$ & Mean (SD) & $2.542(2.73)$ & \multicolumn{2}{|c|}{$0.84(1.28)$} & \multicolumn{2}{|c|}{$1.272(1.74)$} & \multicolumn{2}{|c|}{$3.16(2.88)$} & $0.000 *$ \\
\hline
\end{tabular}

Note: ${ }^{*} \mathrm{p}<0.05$.

Abbreviation: SD, Standard Deviation.

respondents reported performing these two habits without impairment from DED (Table 5).

\section{Discussion}

Our results suggest that DED harms work productivity in both presenteeism and absenteeism, and this is consistent with many previous international studies reporting various degrees of impairment. ${ }^{15,19,20}$ The loss of work productivity due to DED is not negligible, as it was comparable with several other health conditions such as depression, osteoarthritis, back pain, and migraine, according to the Work Limitations Questionnaire. ${ }^{21,22}$

Table 5 Impact of Eye Problems on Daily Activities

\begin{tabular}{|c|c|c|c|c|c|c|c|c|}
\hline \multirow{2}{*}{$\begin{array}{l}\text { Question: Have Problems with } \\
\text { Your Eyes Limited You in } \\
\text { Performing Any of the Following } \\
\text { During the Last Week? }\end{array}$} & \multicolumn{2}{|c|}{ Reading } & \multicolumn{2}{|c|}{ Driving at Night } & \multicolumn{2}{|c|}{$\begin{array}{c}\text { Working on } \\
\text { Computer }\end{array}$} & \multicolumn{2}{|c|}{ Watching TV } \\
\hline & Frequency & Percent & Frequency & Percent & Frequency & Percent & Frequency & Percent \\
\hline None of the time & 59 & $11.5 \%$ & 73 & $14.2 \%$ & 90 & $17.5 \%$ & 74 & $14.4 \%$ \\
\hline Some of the time & 132 & $25.7 \%$ & $|4|$ & $27.5 \%$ & 128 & $25.0 \%$ & 154 & $30.0 \%$ \\
\hline Half of the time & 178 & $34.7 \%$ & 120 & $23.4 \%$ & 130 & $25.3 \%$ & 139 & $27.1 \%$ \\
\hline Most of the time & 58 & $11.3 \%$ & 41 & $8.0 \%$ & 77 & $15.0 \%$ & 68 & $13.3 \%$ \\
\hline All of the time & 49 & $9.6 \%$ & 30 & $5.8 \%$ & 31 & $6.0 \%$ & 40 & $7.8 \%$ \\
\hline NA & 37 & $7.2 \%$ & 108 & $21.1 \%$ & 57 & $11.1 \%$ & 38 & $7.4 \%$ \\
\hline
\end{tabular}

Abbreviations: NA, not applicable; TV, television. 
Although work productivity was impaired across all dry eye severity groups, the degree of impairment was highly variable with different severity levels, and more common in patients with severe DED. The increased impairment of work productivity with increasing severity was also documented by a previous study using OSDI, ${ }^{8}$ and another study using a different way to assess DED severity. $^{23}$

Presenteeism was much more affected by DED than absenteeism, as only a few respondents reported missing working hours due to DED (7.6\%), while $29.4 \%$ of them reported a negative impact on working hours. These findings are consistent with previously published data on physician-diagnosed dry eye participants among whom absenteeism due to DED was uncommon. ${ }^{8}$ Additionally, our findings showed that the performance of daily activities outside of work appeared to be negatively affected by DED, a finding that aligns with the quality of life outcomes of a previous study. ${ }^{24}$

Results from this study support and extend previous findings of the adverse effects of many office-related factors such as computer use and air conditioning, ${ }^{14,25,26}$ as office workers in the present study experienced a severe form of DED (75.2\%) in higher numbers compared to field workers (53\%), and most respondents reported the necessity to stay away from air-conditioning to improve their dry eye symptoms. Some strategies have been documented in the literature to improve DED symptoms among office workers, such as wearing protective eyewear and maintaining appropriate humidity levels. ${ }^{27,28}$ Most respondents experienced a severe form of DED, indicating that people seek medical help only when the symptoms become severe. Therefore, people should be encouraged to get routine checkups for DED, especially office workers, and healthcare professionals should provide them with correct information about DED and its effect on their work performance.

This study had some limitations, including a lack of some demographical variations (eg, most respondents were female, few respondents were older than age 50). Furthermore, the study's cross-sectional design depended on a self-reported questionnaire, and some participants may overestimate their conditions or not describe them accurately. Moreover, the study had no control group, so it was impossible to compare presenteeism with healthy individuals. Despite these limitations, the assessment of work productivity impairment was similar to a previous study with a control group, which indicated a significantly lower working performance in the population with DED than that in the control group. ${ }^{15}$ However, this study represents the first study in Saudi Arabia to explore such an important condition to the best of our knowledge. Moreover, the data revealed some important results and recommendations that may improve our society and our economy.

\section{Conclusion}

In conclusion, DED severity is significantly associated with the impairment of work productivity, particularly among individuals with severe DED, with a higher risk in office workers. Furthermore, this study revealed that DED had a significant negative burden on performing ordinary daily activities such as reading, driving, watching TV, and working on a computer. Therefore, it is important to enhance the awareness of DED and its impact on work productivity among office workers. It is also necessary for healthcare providers to take thorough occupational histories in DED patients and provide the appropriate treatment to improve work productivity and the enjoyment of daily habits that DED may have impacted. DED screening among office workers may also be beneficial as most of the study sample had severe DED, yet only half of them were diagnosed by a physician. Moreover, the study demonstrated that prolonged periods of office work cause severe DED, so it is crucial to emphasize the importance of limiting and reducing office working hours and providing time for rest to reduce the severity of DED and improve work productivity.

Further studies should investigate possible protective measures and lifestyle interventions to improve DED symptoms among office workers and determine the cost of work productivity loss against the medical costs of DED treatments.

\section{Disclosure}

The authors declare no conflicts of interest in this work. This research received no specific grant from any funding agency in the public, commercial, or not-for-profit sectors.

The abstract of this paper was presented at the Annual Research Symposium in King Fahad Medical City, Riyadh, as a poster presentation with interim findings.

\section{References}

1. Courtin R, Pereira B, Naughton G, et al. Prevalence of dry eye disease in visual display terminal workers: a systematic review and meta-analysis. BMJ Open. 2016;6(1):e009675. doi:10.1136/bmjopen2015-009675 
2. Lollett IV, Galor A. Dry eye syndrome: developments and lifitegrast in perspective. Clin Ophthalmol. 2018;12:125-139. doi:10.2147/ OPTH.S126668

3. Messmer EM. The pathophysiology, diagnosis, and treatment of dry eye disease. Dtsch Arztebl Int. 2015;112(5):71-82. doi:10.3238/ arztebl.2015.0071

4. Stern ME, Schaumburg CS, Pflugfelder SC. Dry eye as a mucosal autoimmune disease. Int Rev Immunol. 2013;32(1):19-41. doi:10.3109/08830185.2012.748052

5. Nichols KK, Bacharach J, Holland E, et al. Impact of dry eye disease on work productivity, and patients' satisfaction with over-the-counter dry eye treatments. Invest Ophthalmol Vis Sci. 2016;57 (7):2975-2982. doi:10.1167/iovs.16-19419

6. Tong L, Waduthantri S, Wong TY, et al. Impact of symptomatic dry eye on vision-related daily activities: the Singapore Malay Eye Study. Eye (Lond). 2010;24(9):1486-1491. doi:10.1038/eye.2010.67

7. Uchino M, Uchino Y, Dogru M, et al. Dry eye disease and work productivity loss in visual display users: the Osaka study. $\mathrm{Am}$ J Ophthalmol. 2014;157(2):294-300. doi:10.1016/j.ajo.2013.10.014

8. Patel VD, Watanabe JH, Strauss JA, Dubey AT. Work productivity loss in patients with dry eye disease: an online survey. Curr Med Res Opin. 2011;27(5):1041-1048. doi:10.1185/03007995.2011.566264

9. Stapleton F, Alves M, Bunya VY, et al. TFOS DEWS II epidemiology report. Ocul Surf. 2017;15(3):334-365. doi:10.1016/j. jtos.2017.05.003

10. Alshamrani AA, Almousa AS, Almulhim AA, et al. Prevalence and risk factors of dry eye symptoms in a Saudi Arabian population. Middle East Afr J Ophthalmol. 2017;24(2):67-73. doi:10.4103/ meajo.MEAJO 28116

11. Moss SE, Klein R, Klein BE. Prevalence of and risk factors for dry eye syndrome. Arch Ophthalmol. 2000;118(9):1264-1268. doi:10.1001/archopht.118.9.1264

12. Inomata $T$, Iwagami $M$, Nakamura $M$, et al. Characteristics and risk factors associated with diagnosed and undiagnosed symptomatic dry eye using a smartphone application [published online ahead of print, 2019 Nov 27]. JAMA Ophthalmol. 2019;138(1):58-68. doi:10.1001/ jamaophthalmol.2019.4815

13. Castro JS, Selegatto IB, Castro RS, et al. Prevalence and risk factors of self-reported dry eye in Brazil using a short symptom questionnaire. Sci Rep. 2018;8(1):2076. doi:10.1038/s41598-01820273-9

14. Uchino M, Schaumberg DA, Dogru M, et al. Prevalence of dry eye disease among Japanese visual display terminal users. Ophthalmology. 2008;115(11):1982-1988. doi:10.1016/j. ophtha.2008.06.022

15. Yamada M, Mizuno Y, Shigeyasu C. Impact of dry eye on work productivity. Clinicoecon Outcomes Res. 2012;4:307-312. doi:10.2147/CEOR.S36352
16. Uchino M, Schaumberg DA. Dry eye disease: impact on quality of life and vision. Curr Ophthalmol Rep. 2013;1(2):51-57. doi:10.1007/ s40135-013-0009-1

17. Yamashita M, Arakida M. [Concept analysis of presenteeism and its possible applications in Japanese occupational health]. Sangyo Eiseigaku Zasshi. 2006;48(6):201-213. PMID: 17170514. (Japanese). doi:10.1539/sangyoeisei.48.201

18. Schiffman RM, Christianson MD, Jacobsen G, Hirsch JD, Reis BL. Reliability and validity of the ocular surface disease index. Arch Ophthalmol. 2000;118(5):615-621. doi:10.1001/archopht.118.5.615

19. Sullivan RM, Cermak JM, Papas AS, Dana MR, Sullivan DA. Economic and quality of life impact of dry eye symptoms in women with Sjögren's syndrome. In: Sullivan RM, editor. Lacrimal Gland, Tear Film, and Dry Eye Syndromes 3. Boston, MA: Springer; 2002:1183-1188.

20. Pouyeh B, Viteri E, Feuer W, et al. Impact of ocular surface symptoms on quality of life in a United States veterans affairs population. Am J Ophthalmol. 2012;153(6):1061-66.e3. doi:10.1016/j. ajo.2011.11.030

21. Uchino M, Uchino Y, Kawashima M, Yokoi N, Tsubota K. What have we learned from the Osaka Study? Cornea. 2018;37(Suppl 1): S62-S66. doi:10.1097/ICO.0000000000001731

22. Hemp P. Presenteeism: at work--but out of it. Harv Bus Rev. 2004;82 (10):49-155.

23. Abetz L, Rajagopalan K, Mertzanis P, et al. Development and validation of the impact of dry eye on everyday life (IDEEL) questionnaire, a patient-reported outcomes (PRO) measure for the assessment of the burden of dry eye on patients. Health Qual Life Outcomes. 2011;9:111. doi:10.1186/1477-7525-9-111

24. Mertzanis P, Abetz L, Rajagopalan K, et al. The relative burden of dry eye in patients' lives: comparisons to a U.S. normative sample. Invest Ophthalmol Vis Sci. 2005;46(1):46-50. doi:10.1167/iovs.030915

25. Wolkoff P, Nøjgaard JK, Troiano P, Piccoli B. Eye complaints in the office environment: precorneal tear film integrity influenced by eye blinking efficiency. Occup Environ Med. 2005;62(1):4-12. doi:10.1136/oem.2004.016030

26. Rosenfield M. Computer vision syndrome: a review of ocular causes and potential treatments. Ophthalmic Physiol Opt. 2011;31 (5):502-515. doi:10.1111/j.1475-1313.2011.00834.x

27. Cho HA, Cheon JJ, Lee JS, Kim SY, Chang SS. Prevalence of dry eye syndrome after a three-year exposure to a clean room. Ann Occup Environ Med. 2014;26:26. doi:10.1186/s40557-014-0026-z

28. Blehm C, Vishnu S, Khattak A, Mitra S, Yee RW. Computer vision syndrome: a review. Surv Ophthalmol. 2005;50(3):253-262. doi:10.1016/j.survophthal.2005.02.008
Clinical Ophthalmology

\section{Publish your work in this journal}

Clinical Ophthalmology is an international, peer-reviewed journal covering all subspecialties within ophthalmology. Key topics include: Optometry; Visual science; Pharmacology and drug therapy in eye diseases; Basic Sciences; Primary and Secondary eye care; Patient Safety and Quality of Care Improvements. This journal is indexed on PubMed
Central and CAS, and is the official journal of The Society of Clinical Ophthalmology (SCO). The manuscript management system is completely online and includes a very quick and fair peer-review system, which is all easy to use. Visit http://www.dovepress.com/ testimonials.php to read real quotes from published authors. 